\title{
Symbolic Portrayal of Social Classes in Pakistani Advertisement
}

\author{
Saba Zaidi ${ }^{1}$, Saman Salah ${ }^{1}$, Anisa Tul Mehdi ${ }^{1}$, Mehwish Sahibzada ${ }^{2}$, Durdana Rafiq ${ }^{1}$, Maham $\operatorname{Sultan}^{1} \&$ Samreen \\ Manzor $^{1}$ \\ ${ }^{1}$ English Department, SBK Women's University, Quetta, Pakistan \\ ${ }^{2}$ English Department, Baluchistan University of Information Technology Engineering and Management \\ Sciences, Quetta, Pakistan \\ Correspondence: Mehwish Sahibzada, English Department, Baluchistan University of Information Technology \\ Engineering and Management Sciences, Quetta, Pakistan. E-mail: mehwishsahibzada@gmail.com
}

Received: August 7, 2018 Accepted: September 18, 2018 Online Published: December 29, 2018

doi:10.5539/ijel.v9n1p194 URL: https://doi.org/10.5539/ijel.v9n1p194

\begin{abstract}
The current study aims to identify particular ways through which social actors are represented by Pakistani media such as MCB (Muslim Commercial Bank) Ladies Account (2017). This study is only limited to two Pakistani advertisements as a sample of study. The research design is qualitative content analysis. The study seeks to examine the propagation of class differences for the sake of gaining viewer's empathy in order to achieve marketing purposes. The researchers have applied Leeuwen's (2008) framework of Visual Representation of Social Actor for the analysis of data. The analysis of data has provided an insight into different ways class differences are showcased. It has further provided an insight that notion of lower/middle class is constructed and represented as "others" in the particular advertisements with the help of Visual Representation of Social Actors. The result of study validates that lower/middle class is particularly marginalized in the mentioned advertisements, whereas it has become a general practice of Pakistani media to project such kind of class dichotomy. The study has further incorporated the idea that through such kind of projections the capitalists propagate the purchase of unwanted items. Wherein, regardless of any use the viewers while empathizing with the social actors purchase the advertised items.
\end{abstract}

Keywords: multimodal, advertisement, visual representation, social actors

\section{Introduction}

The study of discourse analysis was previously focused primarily on language and its forms whereas other semiotic resources were ignored. Recently, this view has been changed and discourse has taken a shift by acknowledging the other modes of communication, which contribute to meaning, such as image and visuals. These visuals and images play a vital role in media especially in advertisements.

With the advancement of science and technology, the role of media has undergone through drastic changes along with advertisements. Advertisement is a big business where companies compete to grab viewer's attention and propagate about their particular brands. These companies use simple signs embodied with social norms and ideology. van Dijk (2006) asserts that ideology basically is a kind of idea that is based on a belief system. This study is designed to investigate the influence of Pakistani advertisements in the projection of social classes symbolically through indirect means. This research is important as it has highlighted the ideological construction of social classes through media such as, advertisements.

Advertisements convey messages through images, texts and music. A research conducted by Roberts and Philip (2006) supports that to understand images the comprehension of both verbal and visual literacy is essential. Visual literacy is the ability to interpret meaning from the information presented in an image. Gaskill (2013) asserts visual literacy skills require more than the usage of technology, which is used to teach the skills associated with the meaning. She further says that visual resources in instruction help in developing student's cultural knowledge as well.

According to Leeuwen (2008) Visual images are usually accompanied with social actors conveying implicit meaning of "others" (p. 136). Leeuwen (2008) calls the participants of social practices as "social actor" rather than participant (p. 23). Leeuwen's (2008) framework of Visual Representation of Social Actors emphasizes on the importance of word and image, where word provides facts and image gives vent to interpretation of 
“ideological colored angle" (p. 136).

Leeuwen (2008) further asserts that in advertisements, images give us feeling of glamour and "fulfillment and gratification" (p. 136). The viewers feel pleased to imagine themselves as part of the scenario going on in advertisements. These advertisements sometime convey implicit meanings and visually communicated meanings can be easily dismissed. In advertisement many things are shown according to Leeuwen (2008) advertisements and images can be a mean of showing racism.

\section{Literature Review}

Mostly, the work based on Multimodal Discourse draws from Halliday's Social Semiotic approach to language, a view that considers language as one among a number of semiotic resources such as gesture, images and music through people communicate. According to Leeuwen (2005) Social Semiotics is a form of inquiry and it offers ideas rather than answers, ideas which formulate questions that provide ways to answers. Caldas-Coulthard and Coulthard (1996) support the importance of Semiotics in any text as they say that text cannot be analyzed without considering Semiotic resources accompanied with it, such as images and layout.

Alyousef (2016) in his research employed a Systematic Functional Multimodal Discourse Analysis (SF-MDA) to explore thematic progression patterns in business marketing plan reports. Cheng and Liu (2014) have observed the relationship of $\mathrm{Pi}$ and Richard the tiger in the film Life of Pi by employing systematic functional grammar and functional grammar taking into consideration different Semiotics modalities and their contribution for the conception of film.

Pauwels (2012) explored how contemporary websites become a representative of a culture by engaging a multimodal framework for analysis. Doyle, Freeman and O'Rourke (2017) conducted an interesting research by applying Multimodal Discourse Analysis on online investment regarding crowd-funding pitches and the communication that surrounds them.

Ademilokun and Olateju (2016) in their research have analyzed visual images in political rally discourse and data was analyzed through Halliday's (1985) Systematic Meta-functional Principals. The research validates that colors and images conveyed the ideology and commitment to the political party.

Advertisement leaves a strong impact on viewers and it has become pervasive in the modern capitalist society. Propagation of beauty through advertisements is not an unfamiliar concept. Noriga (2012) applied Multimodal Discourse Analysis to three advertisements in order to understand that how these commercial construct the concept beauty and health related to each other among viewers, focusing on both visual and verbal modes.

Another research conducted by Sharma and Gupta (2015) explores the impacts of advertisements on consumers through Semiotic Analysis. They further argue about the challenges advertisers face while choosing signs, symbols and images in the advertisement to attract the right consumers. In this way it tends to highlight how Semiotics plays a primary role. Advertisements also construct ideology among its viewers and they are vital medium to develop any notion. For instance the study conducted by Adham (2012), investigates the iconic representation of women in the Middle Eastern media through Semiotics. She has explored in detail that how advertisements affect its audience psychologically and how they aid to pursue viewers to adopt a particular course of action. In this way the research intends to unveil the true agenda of media.

Advertisements are often accused of spreading stereotyped ideas due to market requirements. However, a research conducted by Lakshmi and Selvem (2016) is an endeavor to explore advertisements, which try to break away from conventional norms or notions of society through Semiotic Analysis. Rath and Bharadwaj (2014) have also investigated how attributes of gender representation is being deconstruction with the aid of Semiotics. The paper also argues how symbolic ideology regarding role of women and qualities of men have been deconstructed. In this regard Post-Feminism is a famous theory explored by Gowrisankar and Ajit (2016), who attempted to analyze the ideology of Post-Feminism in visual advertisements.

Nonetheless, advertisements are also used for public awareness such as a research conducted by Olowu and Akinkurolere (2015) on Malaria drug advertisement using Multimodal Discourse Analysis has emphasized upon the visual and linguistic components of the selected advertisements. Their data comprised of selected posters, stickers and drug literature advertisements on Malaria. The research proved that color, image, posture and icons enhance the worth of advertisements. Compelling visual images along with sound effect makes an advertisement attractive and grabs viewers' attention. Hu and Luo (2016) conducted a Multimodal Analysis research based on Air France's print advertisements. They explored how Air France conveyed the feeling of grandeur, superiority and comfort using Multimodal Analysis. 


\section{Problem Statement and Research Questions}

This research incorporates a qualitative research design that revolves around the content analysis of selective advertisements as its selected sample. It attempts to present the Visual Representation of Social Actors, which exists in the contemporary advertising media. It further probes into the nature of ways through which these advertisements propagate class differences of Pakistani society. This study attempts to address the following research questions:

Q1. How social classes are projected through Pakistani advertisements?

Q2. How social class is used as a tool to create empathy among the viewers in order to purchase the products?

\section{Method}

The present research is based on the Visual Representation of Social Actors in advertisement in contemporary media in order to examine the representation of class differences. The qualitative mode of inquiry has been preferred, based on the content analysis of two famous Pakistani advertisement selected as a sample of study, MCB (one of the oldest and leading banks in Pakistan) and Pepsi Ramadan Ad. In order to analyze the representation of class discrimination in the selected sample, Leeuwen's (2008) framework of Visual Representation of Social Actors is employed by the researchers.

In defining connection of word and image, Leeuwen (2008) has emphasized about the importance of image and the viewer that is, "how people are depicted and how they relate to the viewers" (p. 137). To investigate both the questions Leeuwen has defined some key elements in his framework. The following three factors are considered in order to question the representation of social actors and their relation to viewers:

a. Social Distance

b. Social Relation

c. Social Interaction

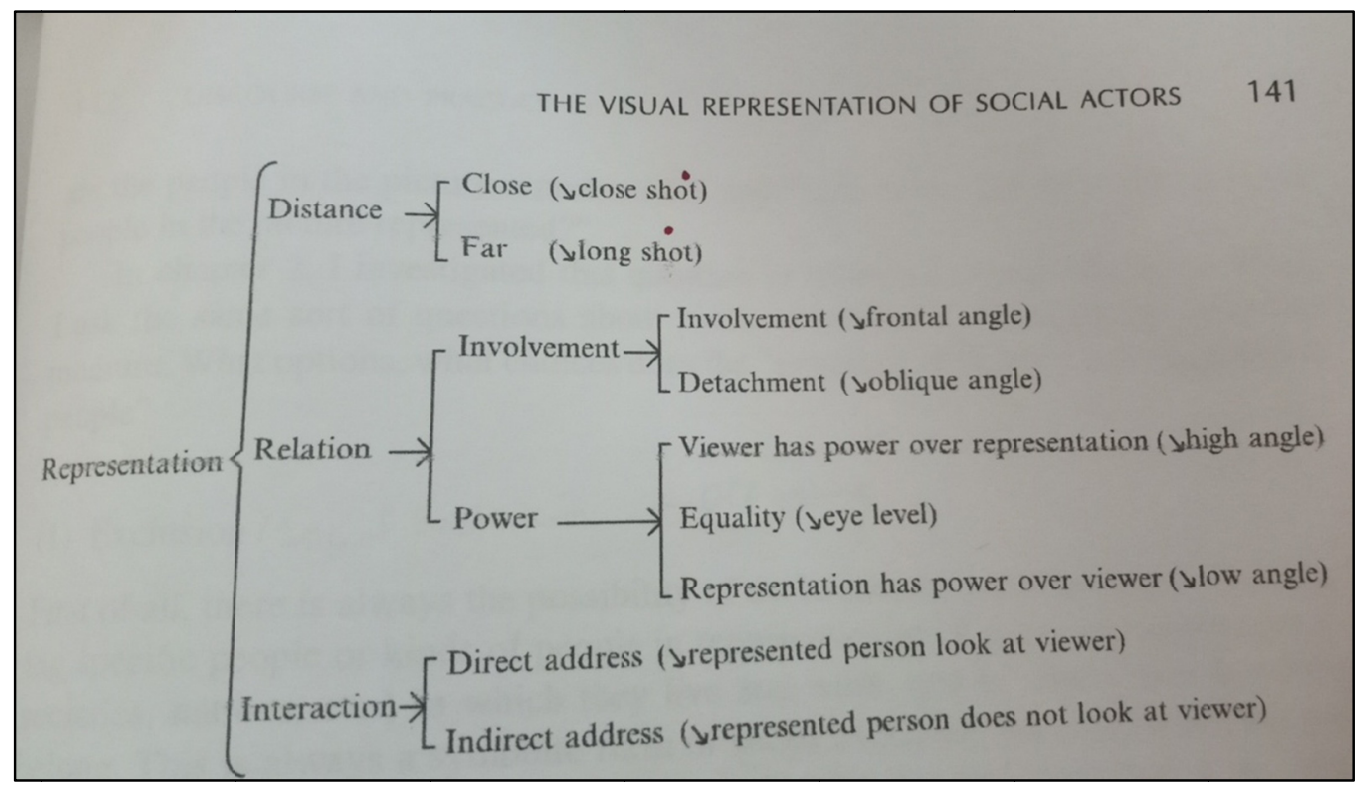

Figure 1. Representation and viewer network (Leeuwen, 2008, p. 141)

The second part of an image that is to depict people he has outlined the following five strategies:
a. Exclusion
b. Roles
c. Specific and Generic
d. Individuals and Group
e. Categorization 


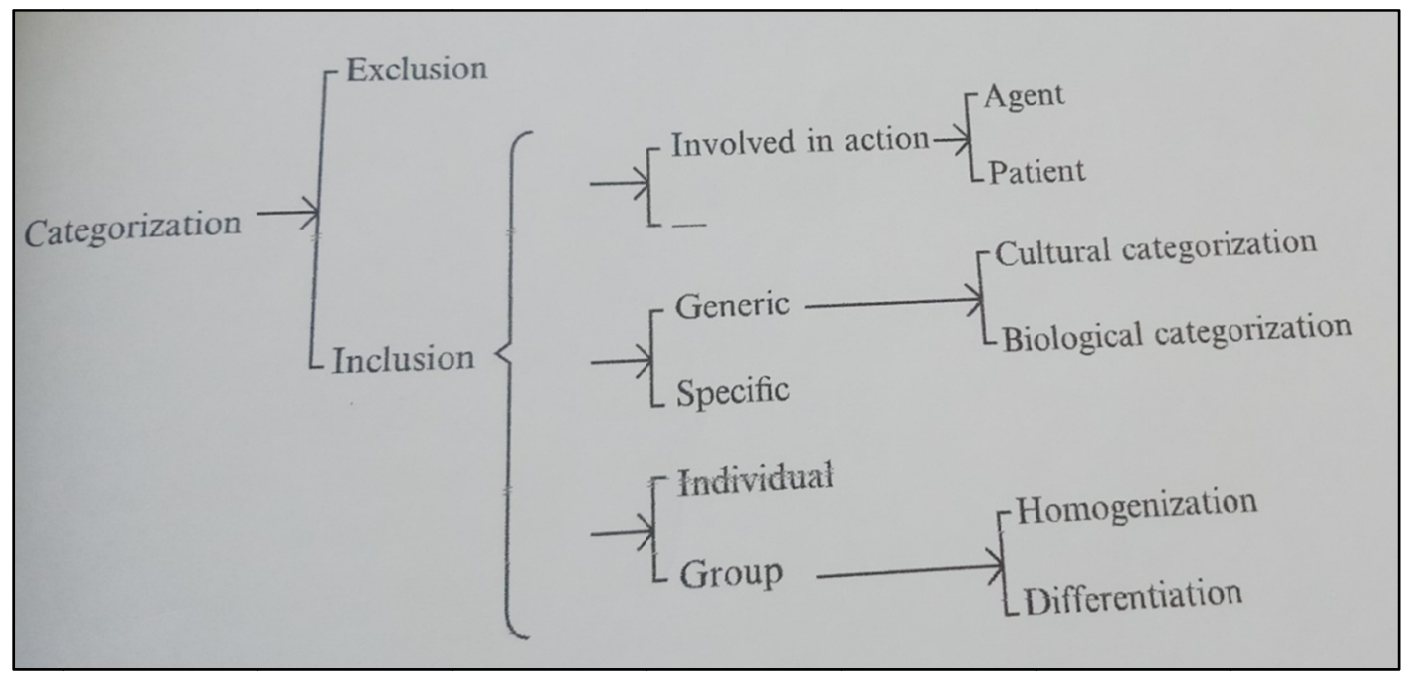

Figure 2. Visual social actor network (Leeuwen, 2008, p. 147)

\section{Results}

The following section is based upon the analysis of data in the light of the above mentioned method and research design.

\subsection{Advertisement Title: MCB (Muslim Commercial Bank) (Ladies Account 2017)}
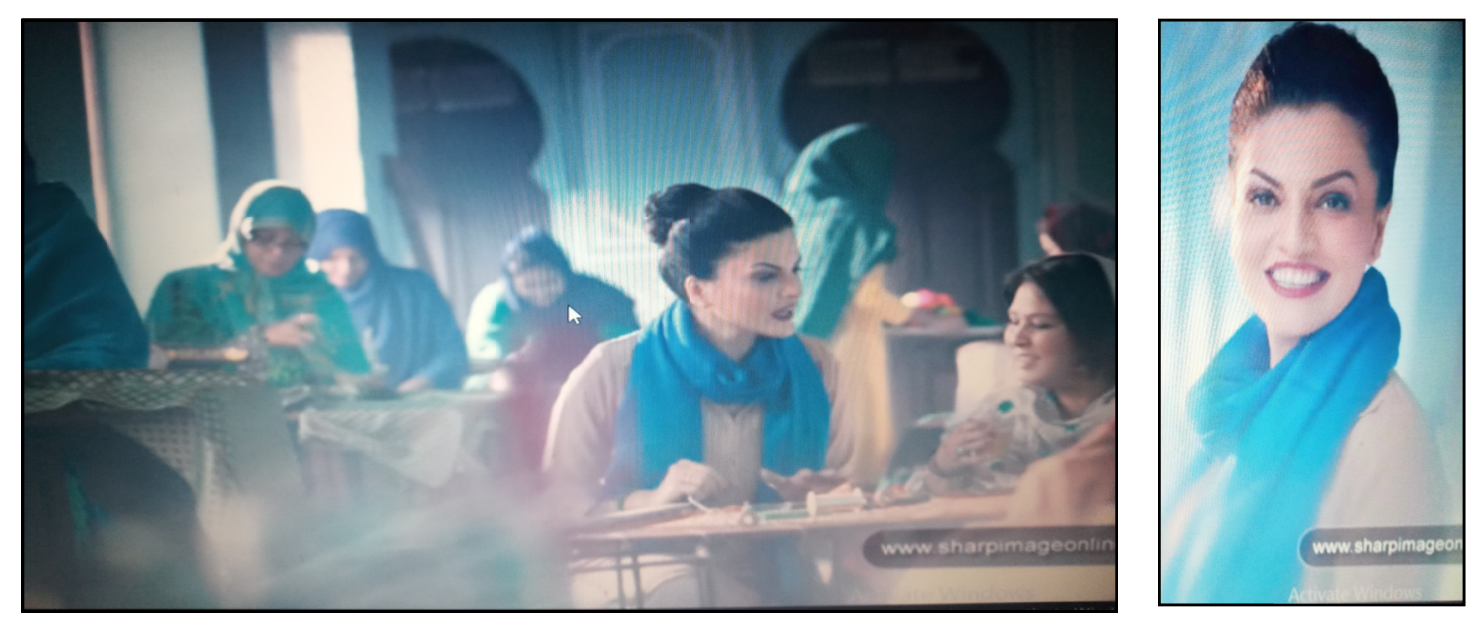

Figure 3. MCB. Ladies Account (2017)

The main crux of the advertisement seems to lie within the verbal commentary initiated by a lady purposefully as this ad is concerned with ladies account, promulgating the attributes of a woman who is accomplished, altruistic and concerned. She is projected as a lady who values frugality and simplicity in life, which suggests the main purpose of this ad that is to urge the ladies to have an MCB Ladies Account. Two images are taken to be analyzed by the researchers to show that how this advertisement has used class differences to gain people's sympathy and attract their interest.

\subsubsection{Social Distance}

The first image shown above demonstrates social distance. As Leeuwen (2008) assets that social "distance becomes symbolic" in pictures (p. 138). The picture is taken from a long shot far away with major focus on the central character. There is a pre-eminent difference between the dressing style of the focused character in the middle and other characters at distance that clearly represents class difference with their head scarves and postures in comparison to the bold gesticulation of the main character. 


\subsubsection{Social Relation}

In the second dimension Social Relation concentrates on power relationships. It is basically an observing angle as mentioned in Table 8.1. The first image is taken horizontally, from an oblique angle, which shows detachment from the people presented in image that comprises of the middle class. The ladies in the image are in long shot, that represents them as not part of us as the distance makes viewers look down to them. The second image is taken vertically in eye to eye contact with camera that shows power of the image as compare to the first image in which ladies are depicted as part of lower or middle class.

\subsubsection{Social Interaction}

The third dimension is regarding Social Interaction, which observes whether social actors in the image look at the viewers or not. In the aforementioned vertical image not a single lady is looking at the viewers in other words, not communicating. The whole image gives us a notion that these ladies are weak, uneducated and uncivilized, and they want someone to help them financially. While in the second image the social actor has maintained a direct gaze with the camera thus addressing directly to viewers as she is close to the viewers.

In the second part how people are depicted? Five strategies have been defined and those strategies are given below:

\section{- Exclusion/ Othering}

- Role

- $\quad$ Specific and Generic

- Individuals and Groups

- Categorization

In the aforementioned advertisement all the ladies are wearing head scarves except one woman. This shows the stereotyped representation of middle or lower classes, portraying them as others. These ladies are shown as involved in an action of sewing, working and serving, which conveys the implosive message that all the middle class or lower class ladies depend on sewing and other such manual works for their livelihood. These ladies are represented as a specific group, representing specific class. Whereas the rich lady in the middle of the image is captured individually representing her high social class as a group. If we observe how image is visually categorized, we see here cultural categorization, as their head scarves represent a culture as well as a specific class in Pakistani context. One woman is looking different due to the reason of not wearing scarf but modern attire. On the other hand, there is a second image where the woman is individualized and represented as a specific person by being separately framed as well, looking directly towards viewers with a broad smile. If we take biological categorization, all the ladies have ordinary features that have made them a homogeneous group in comparison to central character who is shown as a beautiful and distinctive lady.

\subsection{Advertisement Title: Pepsi Ramadan Ad. 2017 - Pepsi Liter of Light - Pepsi Pakistan}
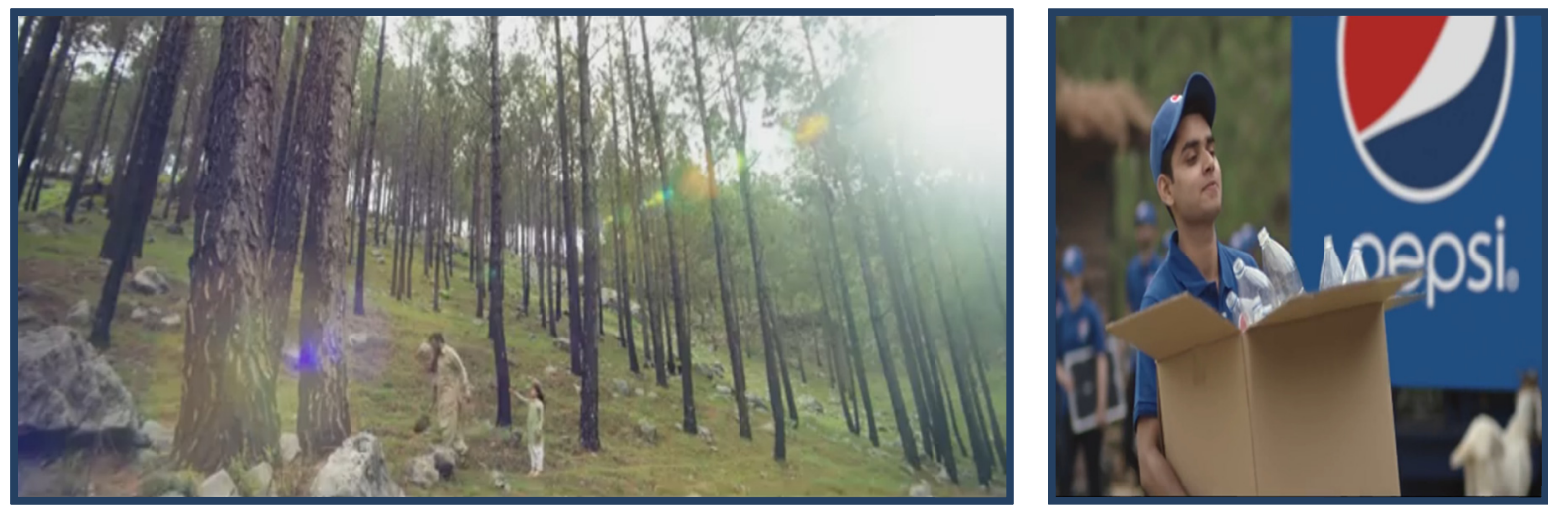

Figure 4. Pepsi Ramadan Ad. (2017)

The story depicted in the advertisement revolves around a girl who belongs apparently to lower middle class, whose father seems to be a daily wager. Since her father has to go to work covering long distance, she wants him to come back home safely in the darkness of the night. This idea projects the main aim that is to gain empathy of 
the viewers for the sake of selling product as well as leaving a positive notion about product in the minds of viewers.

\subsubsection{Social Distance}

The first image speaks for itself regarding social distance, which is a long shot. The central characters are barely visible at first glance in the vast land scape. The long shot also gives the message to viewers that the social actors represented in the shot are not significant, so the viewers cannot relate to them. This represents the distance between the viewers and characters symbolically. Moreover social actors are shown in ordinary dresses, reinforcing the depiction of lower middle class. In contrast the second image comprised of close shot that focuses on the stylishly dressed person along with the logo of a company in the back ground. The focused stylish individual is a kind of persona to which the viewer especially young generation can easily relate to.

\subsubsection{Social Relation}

As Leeuwen (2008) asserts that social relation is concerned about power. It discusses either power of representation over viewer or viewer's power over image. The first image is taken horizontally from an oblique angle, showing detachment. In this way viewers do not relate to the characters portrayed in the image. They are "others" for the viewers. The image gains power not only by depiction of characters but also from the point of view of angle. Viewers are looking down to them, thus gaining power over image. Thus, the depicted characters as socially below to the viewers.

\subsubsection{Social Interaction}

In both the images social actors are not looking at the viewer's directly thus, they are not communicating with the viewers. First image gives an idea to the viewers that this could be happening somewhere far from them, not near them. In this way they do not feel affiliation with the characters neither do they feel empathy. Whereas, the second image instantly gives the sense of familiarity due to close angle.

\section{- Exclusion/ Othering}

- Role

- $\quad$ Specific and Generic

- Individuals and Groups

\section{- Categorization}

Lower middle class has been portrayed as other in the image by presenting them in a typical dress style as compared to other image dressed entirely in western outfits. This kind of symbolic representation depicts different cultures as well as classes. Lower middle class is assigned the role of a working class as daily wagers. These people are supposed to leave their family and children behind for work at times they even endanger their lives. The social actor in the second image is shown through a close shot that has categorized him as a significant individual. On the other hand lower middle class is treated as a generic group regardless of any signification.

\section{Discussion}

An analysis of the above mentioned advertisements, using the framework of Leeuwen (2008) truly reveals that Visual Representation of Social Actors in the advertisements have an influential role in the lives of the viewers. The analyzed advertisements have aptly projected class distinction mainly focusing on the lower, middle and upper classes. The advertisement has equally displayed the feelings of empathy among the viewers in order to acquire the MCB bank accounts for the gratification of their needs and to become like the upper class educated lady shown in the advertisement. In the light of the above discussion it can be concluded that viewers accept the impact of such images and portrayal of class discrimination, consequently they get influenced by the charm and success of upper class. In this way an advertisement carries an "ideology", and "ideology" leaves a long lasting impact on the lives of individuals. However, this research is limited to just two advertisement based upon qualitative content analysis. Future researchers can carry such researches based upon more advertisement along with the quantitative mode of inquiry.

\section{References}

Ademilokun, M., \& Olateju, M. (2016). A Multimodal Discourse Analysis of Some Visual Images in the Political Rally discourse of 2011 Electioneering Campaigns in Southwestern Nigeria. International Journal of Society, Culture and Language, 4(1), 1-19.

Adham, S. A. (2012). A semiotic Analysis of Iconic Representation of Women in the Middle-Eastern Media Doctoral Dissertation, Tesis. United Kingdom: The University of Birmingham. 
Alyousef, H. S. (2016). A multimodal of discourse analysis of the textual and logical relations in marketing texts written by international undergraduate students. Functional Linguistics, 3(1), 3. https://doi.org/10.1186/s40554-016-0025-1

Caldas-Coulthard, C. R., \& Coulthard, M. (Eds.). (1996). Texts and Practices: Reading in Critical Discourse Analysis. London, New York: Routledge.

Cheng, Y., \& Liu, W. (2014). A Multimodal Discourse Analysis of the Relationship between Pi and Richard the Tiger in the Movie Life of Pi. International Journal, 2(4), 191-219. https://doi.org/10.15640/ijll.v2n4a11

Doyle, V., Freeman, O., \& O'Rourke, B. (2017, June). A Multimodal Discourse Analysis Exploration of a Crowdfunding Entrepreneurial Pitch. In ECRM $201716^{\text {th }}$ European Conference on Research Methods in Business and Management (p. 415). Academic Conferences and Publishing Limited.

Gaskill, N. C. (2013). Visual Literacy, Standards, and the Use of Visual Resources in Schools. Retrieved from Centralspace.ucmo.edu

Gowrisankar, D., \& Ajit, I. (2016). Ideology of Post-Feminism: Portrayal through Visual Advertisements in India. Global Media Journal, 14(27). Retrieved from http://www.globalmediajournal.com/open-access/ideology-of-postfeminism

Hu, C., \& Luo, M. (2016). A Social Semiotic Analysis of Air France's Print Advertisements. International Journal of English Linguistics, 6(4), 30. https://doi.org/10.5539/ijel.v6n4p30

Lakshmi, C., \& Selvam, V. (2016). Challenging Stereotypes: A Simiotic Analysis of Indian Advertisements. Asian Journal of Research in Social Sciences and Humanities, 6(11), 907-924. https://doi.org/10.5958/2249-7315.2016.01239.9

MCBPK. (2017, May 17). MCB Ladies Account TVC - YouTube. Retrieved from https://www.youtube.com/watch?v=bfMHBIFHEJ8

Noriega, A. (2012). The Conflation of Health and Beauty in Advertising: A Critical Multimodal Discourse Analysis of Three Television Commercials (Doctoral dissertation, Carleton University Ottawa).

Olowu, A., \& Akinkurolere, S. O. (2015). A Multimodal Discourse Analysis of Selected Advertisement of Malaria Drugs. English Review: Journal of English Education, 3(2), 166-173

Pauwels, L. (2012). A Multimodal Framework for Analyzing Websites as Cultural Expressions. Journal of Computer-Mediated Communication, 17(3), 247-265. https://doi.org/10.1111/j.1083-6101.2012.01572.x

Pepsi Pakistan. (2017, May, 27). Pepsi Liter of Light 2017 [Video File]. Retrieved from https://www.youtube.com/watch? $\mathrm{v}=\mathrm{z} 3 \mathrm{Q} 4 \mathrm{gPAIwI} \& \& \mathrm{t}=111 \mathrm{~s}$

Rath, P., \& Bharadwaj, A. (2014). Deconstructing Symbolic Ideology in Contemporary Communication Strategy in Advertising: The Case of Nirma and Wheel. IIMB Management Review, 26(1), 17-27. https://doi.org/10.1016/j.iimb.2013.12.001

Roberts, S., \& Philip, R. (2006). The Grammar of Visual Design. Australasian Journal of Educational Technology, 22(2), 209-228. https://doi.org/10.14742/ajet.1299

Sharma, P., \& Gupta, P. (2015). Semiotic Analysis of Indian Television Advertisements and its Impact on Consumers: An Exploratory Study. Journal for Communication Studies, 8(1), 71-90. Retrieved from https://www.ssoar.info/ssoar/handle/document/45768

Van Dijk, T. A. (2006). Ideology and Discourse Analysis. Journal of Political Ideologies, 11(2), 115-140. https://doi.org/10.1080/13569310600687908

Van Leeuwen, T. (2005). Introducing Social Semiotics. London, New York: Routledge.

Van Leeuwen, T. (2008). Discourse and Practice: New tool for critical discourse analysis. UK: Oxford University Press. https://doi.org/10.1093/acprof:oso/9780195323306.001.0001

\section{Copyrights}

Copyright for this article is retained by the author, with first publication rights granted to the journal.

This is an open-access article distributed under the terms and conditions of the Creative Commons Attribution license (http://creativecommons.org/licenses/by/4.0/). 